\section{A forum to discuss the 1983 Mental Health Act for medical and social work professionals}

\section{DEAR SIRS}

The 1983 Mental Health Act ${ }^{1}$ places obligations and responsibilities on both the health and social services to act individually and jointly in the admission of patients to hospital, their care whilst in hospital, and their after-care.

The local authority Social Services Department and Haringey Health Authority do not provide a multidisciplinary team as a resource for mentally disabled people and it became evident that doctors and social workers needed the opportunity to debate the issues of policy and practice surrounding the 1983 MHA. Accordingly, in 1985 a joint initiative was set up by a senior social worker and a consultant psychiatrist, which was appropriately named the Mental Health Practitioners' Forum. The 'Forum' is now in its third year and is run on a sessional basis from October to August, meeting every six weeks. Membership is drawn from both practitioners and management within the local Social Services and Health Departments. The group centres on a core of consultant psychiatrists, junior doctors, charge nurses, social workers from the community and the hospital, the hospital administrator, a local GP, community psychiatric nurses, the Health Service Minority Ethnic Liaison Officer and social workers from after-care resources. Others, such as police and ambulance service representatives, are invited as appropriate.

At the first meeting of a series, suggestions are made for discussion topics at future meetings. Three or four related items then serve as an agenda for the next meeting. The only restriction on these items is that each has a bearing upon the Mental Health Act or its implementation.

Topics have included practice surrounding the use of Section 136 ('Police' 72 hours), both from the police angle and that of the social worker and duty doctor; the relative uses of Section 2, 3 \& 4, medical and social work aspects; Section 132 (patients' rights) with emphasis on informing patients who do not speak English; the use of Section 135 (warrants to enter private dwellings); risk taking when assessing patients for sections, staffing implications; follow-up procedures for patients assessed for section but not sectioned; the mechanics and uses of 'nearest relative' applications; procedures for compulsory admission for patients in the out-patient department; communication and liaison between GPs, psychiatists, social workers, ambulance and police services in performing the section procedure; legal representation for patients under compulsory section; the implications of the 1983 MHA on people from ethnic minorities; compulsory treatment in the community and the proposed 'Community Section'; the ethics of sectioning demented patients; the role of the GP in compulsory section and follow-up; the role of CPNs in section assessment and follow-up.

As this list demonstrates, there is never a shortage of subject matter, and each topic yields a beneficial interchange of views.

At such times as the agenda included, for instance, items relevant to the police, we extended an invitation to the local Metropolitan Police who kindly sent along two Chief Inspectors as representatives. A debate about the ambulance service and its responsibilities and availability was attended by the London Ambulance Service Liaison Officer. A discussion concerning language difficulties and ethnic minorities was attended by the Health Service Minority Ethnic Liaison Officer, and so on.

Through the debates the 'Forum' has related practice issues and experiences to the policies of the Mental Health Act. For example, the after-care responsibilities laid down in Section 117 have been highlighted as a joint social services and medical responsibility.

The special needs of people from ethnic minorities have been a regular part of our discussions. The 'Forum' has lent its support to a developing advocacy scheme for patients from minority groups and has pressed for 'Patients' 'Rights' leaflets to be available in a range of languages.

The need for this 'Forum' has been justified by its continuation for three years, its good attendance, and enthusiastic debate. It provides a relaxed meeting place for professionals, and even serves the unusual function of encouraging the voicing of different opinions within a single discipline. It appears to have sufficient structure for debate to be constructive and instructive and is never stultified by excessive formality or a hurried agenda.

It is difficult to assess the impact of the 'Forum' on the Social Services Department and the Health Authority as a whole. While not being a formal policy-making group, the minutes of our debates are circulated to those involved in creating a new local health service through the hospital closure programme. The 'Forum' has contributed to the debate on open ward policy.

The purpose of the 'Forum' is to promote good practice amongst those working in the field. In this sense it works as a training resource for practitioners where information can be shared, grey areas of practice clarified, and joint working initiatives established.

A major effect of the 'Forum' has been on the quality of service delivery. Patients and clients receive a more considerd and efficient service 
through opening up channels of communication between doctors, social workers and others, where each professional becomes aware of his role and that of his colleagues.

The 'Forum' not only enables faces and personalities to be attached to voices at the end of a telephone but also leads to fruitful debate and an improved basis for understanding each other's needs in the practice and enactment of the 1983 Mental Health Act.

London Borough of Newham Social Services

JONATHAN WATKINS

Friern Hospital, London N11

ADRIAN YonACE

Reference

${ }^{1}$ Mental Health Act 1983. London: HMSO.

\section{'Child psychiatry, white elephant, Scotch mist or medicine?'}

DeAR SIRS

I write to support Professor Taylor's case for a doctor to act like doctor in the child psychiatric team (Bulletin, June 1988).

Seventeen years ago, my son, who had passed the 11 Plus Examination and had started at a grammar school, lagged seriously behind the rest of his class and became over-active and aggressive at home. He was impulsive, unpredictable and kept running away.

Our general practitioner, who had a strong bias towards a psychodynamic approach to such problems, referred us to the family therapy department of a famous Institute. There, undeniable tension between his parents was uncovered, and it was also noted that, being of average intelligence, he could have difficulties in coping with a grammar school, despite or because of parental ambitions. He was labelled maladjusted and arrangements were in hand for him to attend an appropriate boarding school for the maladjusted.

One weekend, a psychiatrist friend of the family visited, and noticed that our son was quite different from his normal self. The change was qualitative rather than quantitative. Consequently he was seen by a neurologist and EEG confirmed the diagnosis of temporal lobe epilepsy. The behaviour disorder responded rapidly to treatment with phenytoin and carbamazepine, complemented by chlorprozamine, and having lost a term from school he was able to go back to school (though not the original grammar school) the next term. For the past few years he has been off all medication and free from further seizures.

I am not disputing the dynamic contribution to our son's problems, but the key disorder was cerebral and responded to appropriate therapy. No physical examination was made by the GP or the specialist team to which our son was referred, and we as guiltridden parents did not press for one until our friend spotted the true nature of the disorder. Had that diagnosis not been made the subsequent course of the disorder might have been very different.

Professor OF Psychiatry (name and address supplied)

\section{DeAR Sirs}

I welcome the spirit of Professor David Taylor's reaffirmation of the need for physicianly skills in the child psychiatrist's repertoire, but I think he does not go far enough. Child psychiatry is by its very nature a multidisciplinary craft, and the psychiatrist is the one whose duty it is to keep the whole process in view. The path of a patient, from 'complaint' and 'referral' to 'discharge' and 'follow up', via 'allocation', 'consultation', 'assessment', 'treatment' and/or 'recommendation', is a long one with many choices and turnings on the way. What Professor Taylor describes as "the pursuit of the medical model in its more general sense' is, in my opinion, the reviewing of this route in every case which includes, but is broader than, working 'through possibilities in genetics, obstetrics, neonatology, paediatrics and child development' which he describes. Others in the clinical team may take equal or greater interest in such reviews, from their own professional standpoint. What I am saying is that the psychiatrist is the one who is obliged to do so.

Sebastian Kraemer Conjoint Training Programme in Child, Family and Adolescent Psychiatry, Tavistock Clinic London NW3

\section{Return of abused children to their parents}

DeAR Sirs

Dr Dunn's letter (Bulletin, July 1988, 12, 290) poses an interesting question about the relevant skills to be acquired by psychiatrists.

One view might be that our profession only needs to know about scientifically-corroborated diagnoses of formal mental illness and that this should be the main focus of training. Such a psychiatrist would, indeed, have little to offer courts, social workers, paediatricians and families trying to resolve problems of child abuse.

Another view is that psychiatrists should be knowledgeable about nuances of personality and relationships and conflicts which influence their development. 